\title{
Modernización Económica y Sindicalismo en México1987-1992
}

\author{
Juan Bravo Zamudio \\ Unidad Académica Profesional Zumpango. UAEM
}

\section{Introducción}

Este ensayo es una primera versión $y$ forma parte de un proyecto de investigación más amplio que está en proceso de elaboración.

El objetivo del presente es el de fundamentar la metamorfosis que se da o se está dando en el sistema de relaciones $y$ vinculaciones entre la élite estatal mexicana $y$ la élite (burocrática) sindical, cansada por el cambio de la política económica aplicada a mediados de la década de los 80's, dada la crisis financiera externa padecida por el país a inicios de la década.

\section{I}

En la década de los ochenta, México vivió una de sus más graves crisis económicas de su historia posrevolucionaria. Esta crisis, la de 1982, se mostró como una crisis financiera externa.

Como se recordará la década pasada se distinguió por la crisis de la deuda externa del mundo periférico, teniendo a América Latina como centro del terremoto, aunque no exclusivamente de ella.

Esta situación acaparó la atención del mundo por la peligrosidad que significaba la amenaza de crisis al sistema financiero internacional por un lado y por otro lado un brutal rompimiento y posible confrontación entre el Norte y Sur, cuyos costos para todos serían altísimos.

Para ubicar el problema en el caso mexicano, recordaremos algunas decisiones gubernamentales que se tomaron en materia económica. José López Portillo, en los inicios de su administración, al tener evidencia de que el empleo y salarios en el área industrial habían descendido durante 1977 (Bortz y Sánchez: 1985), se percató de que el ahorro interno era demasiado bajo y las inversiones externas directas en la economía eran insuficientes, y que ambos no le garantizaban financiar un crecimiento rápido y permanente, por ello el 
presidente se decidió acudir a los préstamos al extranjero, que en los años recientes había sido un recurso que funcionó, sintiendo que en esos momentos tenía el respaldo para ello de las recién descubiertas nuevas reservas petroleras del país (Bortz, $1991: 52$ ).

A partir de ese instante la industria petrolera significaba la punta de lanza de la estrategia económica Lopezportillista. La tarea consistía, entonces, en la rápida y exponencial expansión de la explotación del petróleo con los recursos prestados del extranjero, a fin de que el crecimiento y consolidación de esta industria articulara y gravitara sobre el desarrollo de la economía en su conjunto, con lo cual se pretendía resolver el problema histórico del empleo del país.

Sin embargo, en los años 1981 y 1982 se presentaron las complicaciones para el régimen, a mediados del primer año el precio internacional del petróleo bajo un 10\% (Bortz, 1991:53).

Con respecto a la deuda externa gubernamental, ésta "alcanzó los quince mil millones de dólares durante ese año (1981) y la deuda del sector privado, más de cuatro mil millones. Para sostener el peso, el régimen contrató en 1981 más deuda externa de la que había adquirido entre 1975 y 1980". (Bortz, 1991)

Ante esta situación José López Portillo decretó aumento de precios a los bienes y servicios de consumo básico, tratando de reducir los subsidios otorgados. El banco central abandonó nuevamente el mercado cambiario, dejando flotar al peso hasta que encontrase su valor real.

En el octavo mes del año de 1982, el secretario de Hacienda acudió a la ciudad de Nueva York para obtener una prórroga de 90 días para un pago de cerca de 10,000 millones de dólares de deuda de corto plazo, que estaba por vencerse (Bortz, 1991:54)

En su último informe presidencial, López Portillo anunciaba a la sociedad mexicana que el país se encontraba en plena bancarrota, que estaba por darse otra devaluación $y$ se nacionalizaba la banca privada.

El mes anterior a la entrega de los poderes federales, a la nueva administración, el encargado del ministerio de Hacienda firmaba un acuerdo con el Fondo Monetario Internacional, en el que se establecía bajar el déficit público del 16.5 al 8.5\% del PIB en un plazo no mayor de un año, elevar los precios de bienes $y$ servicios del sector público, incremento del ahorro de los sectores públicos $y$ privados $y$ reducir los niveles de protección a la economía. (Bortz, 1991)

El nuevo gobierno instrumentó un programa anticrisis, cuyos pilares centrales tenían como objetivo prioritario negociar un acuerdo con los acreedores de México, buscando aligerar un poco la pesada deuda externa que se 
cernía sobre el país a fin de disminuir su monto y controlar la inflación galopante. Este era un típico programa de política de ajuste para la estabilización de la economía y consistía en reducir el déficit de la balanza de pagos $y$ disminuir la tasa inflacionaria a niveles compatibles con el crecimiento sostenido. (Cortés, 1991: 12)

La política de salarios e ingresos se convirtió en el eje fundamental en la lucha contra la inflación. El gobierno controlaba directamente el salario mínimo legal y el salario de la burocracia federal. En los dos casos siempre buscó que los incrementos a ellos estuvieran por debajo del índice inflacionario, con el objeto de que el factor salario no se convirtiera en un incentivo al incremento generalizado de los precios.

$\mathrm{Al}$ mismo tiempo el propio gobierno presionaba a los privados, tanto el capital como al trabajo, para que los salarios contractuales no rebasaran el incremento asignados a los mínimos.

Simultáneamente a lo anterior, una medida adicional al programa de ajuste, que era un programa de austeridad, fue la reducción del gasto del sector público, principalmente en el rubro de lo social, y del propio sector público. Esto significó una redefinición del sistema paraestatalizado, en el cual el gobierno decidió desprenderse de algunas empresas, cuyos costos de mantenerlas eran mucho más altos que los beneficios que generaban, transfiriéndolas al sector privado. Asimismo, a través del comercio y la liberación de la economía se pensaba presionar a los empresarios a ser más eficientes y productivos, dado que competirían con sus pares externos que producían a menores costos. (Bortz, 1991:55- 56)

En sus inicios y en algunas áreas del programa de lamadridista pareció funcionar, sin embargo, en el resultado final de su administración, entre malas cuentas al país. Si bien no se dejaron de cumplir con los compromisos establecidos con los acreedores externos, la inflación, a pesar de controlarla, no cedió, el problema de la deuda externa no se resolvió como se esperaba, al contrario, se incremento durante el sexenio y se presentó una fuerte presión, en cuanto a restricciones económicas, para el régimen. (Bortz, 1991:56)

Ahora bien, al decidirse por el pago del servicio de la deuda externa, los efectos fueron los siguientes:

a) Transferencia de recursos al exterior, adelgazando fuertemente el ahorro mexicano, que encadenado a la dependencia de la importación de equipo y bienes de capital, comprimieron el potencial de crecimiento económico.

b) Al utilizarse los recursos internos para los pagos del exterior, y al no hacerlo mediante una política fiscal, el gobierno echó mano del recurso del impuesto inflacionario. 
c) La combinación de los dos puntos anteriores trajo como consecuencia el descuido de la desatención de la inversión productiva, provocando un impacto social demoledor sobre la población, sustancialmente, en el nivel de ingreso, en la oferta de trabajo, en la capacidad adquisitiva y en la liberación de precios a través de la quita de subsidios.

Dada esta situación, el país para 1987 se encontraba al borde de la hiperinflación, debido a la conjunción de varios problemas, ya indicados arriba, y que el programa de política de ajuste no fue capaz de sortear. En diciembre de ese año se anunciaba e instrumentaba un nuevo programa de gobierno: el Pacto de Solidaridad Económica (PSE). Este nuevo programa era de cambio estructural, que se implementa a fin de estimular la eficiencia productiva necesaria para el crecimiento sostenido. (Cortés, 1991: 12)

Dicho programa contemplaba por un lado mantener los aspectos positivos del programa de austeridad de lamadridista, y por otro lado signar un nuevo pacto social, para obtener nuevos acuerdos con las representaciones empresariales, obreras y campesinas en materia de tasa de cambio, salarios y precios de los bienes y servicios público y privados. Además de intentar amplios cambios estructurales en la economía vía liberalización del comercio, desregularización y redefinición del rol del sector público. (Bortz, 1991:60)

Una vez presidente, Carlos Salinas reemplazó el PSE por el Pacto para la Estabilidad y Crecimiento Económico (PECE), que fue una manera de reafirmar el programa o política de cambio estructural.

Una parte significativa de dicho programa fue la continuación estratégica de mantener los aumentos salariales por debajo de las tasas inflacionarias dadas y anticipadas, con lo cual los salarios reales cayeron considerablemente.

El programa de recuperación de Salinas de Gortari parece haber sido exitoso en comparación con los de sus antecesores -sobre todo en el plano macroeconómico-pero los datos e información indican que esa recuperación fue para el capital y no para el trabajo. (Bortz, 1991:63)

En materia de empleo en los años 1987-1990, éste no fue suficiente como para contrarrestar ni el déficit de empleos heredados de las últimas cuatro décadas, ni la acentuación del desempleo y subempleo a lo largo de la década de los 80 's. La estimación indica que el $12 \%$ de la fuerza de trabajo mexicana estaba desempleada, y el $40 \%$ subempleada. (Sodi, 1990)

Sin embargo, se ha hecho manifiesto un crecimiento continuo del llamado empleo marginal en los servicios urbanos y en las actividades artesanales. Durante 1979, según datos oficiales, hay una pequeña disminución en el desempleo abierto en las áreas urbanas de México, y al mismo tiempo un 
incremento significativo de los “trabajadores autoempleados”, que en México es una categoría que incluye a muchos de los trabajadores marginales del país. (NAFIN- SA, 1990: 19)

Ahora bien, el comportamiento de los salarios ha sido a la baja en los año 1987-1989, no obstante el repunte, aunque ligero, del crecimiento y el empleo. En este renglón los datos al respecto son contradictorios. Los salarios reales en el área industrial cayeron $1.5 \%$ en 1987 y $0.4 \%$ en el siguiente año. Pero, entre el tercer trimestre de 1988 y el tercer trimestre de 1989, el salario mínimo real cayó $4.5 \%$, y a finales de este último año el mismo salario había perdido más del $50 \%$ de su capacidad adquisitiva con respecto a 1978 (Bortz, 1991:65).

Durante el período en que se diseñaron y aplicaron las políticas económicas de corte anticrisis, instrumentada por Miguel de la Madrid, a través de los "programas de ajuste" en los años 1983-1986, y sobre todo a partir de 1987 cuando se implementa un nuevo tipo de programas, dada la gravedad de la economía mexicana, conocidos como "cambio estructural", se genera una nueva situación sociopolítica en el país que hace que se modifique la vieja alianza entre élite estatal y élite sindical, de cuño cardenista, que data de la década de los treintas, pero sin romper la matriz corporativa, que es la base de esa alianza.

Pero, entonces que cambió? o qué se modificó de esa alianza? Es precisamente esto lo que nos proponemos investigar, cuya formulación es la siguiente: el paquete de decisiones y acciones tomadas por el gobierno desde 1987 a la fecha en materia económica, que suponemos es el proyecto de modernización ${ }^{1}$ económica del régimen salinista, cómo han afectado las relaciones y alianzas - que se establecieron en los años treinta- entre la élite estatal y la élite sindical actuales, dentro del armazón corporativista.

A partir del régimen de Lázaro Cárdenas y los posteriores a él la relación típica que se estableció entre ambas -élite estatal y élite sindical- era una relación que implicaba un intercambio de bienes y servicios en el cual las corporaciones sindicales recibían beneficios económicos y sociales y otorgaban a cambio lealtad, apoyo político, garantía de votos al PRI y colaboración, en una palabra consenso, a las acciones y decisiones estatales. (Hernández, 1992: 152)

1 Entendiendo por modernización económica del régimen de Salinas, el proyecto de cambio estructural que busca la eficiencia productiva a fin de lograr el crecimiento sostenido y permanente de la economía del país. Si bien ya en páginas anteriores hemos señalado algunas de decisiones y acciones que conforman el proyecto modernizador en materia económica, es necesario definirla y detallarlo más en que consiste, cuestión que se hará más adelante. 
En este sentido, el corporativismo operó como un sistema de intermediación de intereses y representación de intereses.

Si bien el desarrollo no alcanzó a todo por igual, el hecho es que los beneficios existieron y fueron distribuidos a través de las organizaciones corporativas. Por su parte el Estado no mantuvo una relación directa con la sociedad, no entregó los bienes a los ciudadanos, sino que empleó a las corporaciones como intermediarios. Aparentemente o formalmente eran ellas las que gestionaban, proponían o conseguían la resolución de alguna demanda, y en otras ocasiones sólo era el canal de decisiones del Estado. En cualquier caso, eran ellas encargadas de cosechar los frutos.

"Salud, educación, empleo, salarios, vivienda, etcétera, llegaron a los sectores sociales a través de las organizaciones que los agruparon, aparecieron como resultado del compro- miso estatal con el mejoramiento de las condiciones de vida, pero también como la eficaz capacidad de negociación y, por lo tanto, de representación de los organismos. A ellos correspondió la tarea de transformar esos beneficios en apoyo para el régimen en dos sentidos distintos, pero complementarios: para las corporaciones misma y sus líderes, porque demostraban ante los agremiados buen desempeño político, y para el Estado, porque más tarde traducirían el agradecimiento de sus agremiados de sus miembros en votos por el partido"(Hernández, 1992: 154) los propios cargos electorales fueron una prenda más para comprometer la lealtad de la élite sindical.

Esta red de relaciones se puede entender como canal de regulación sistémica, en donde toda práctica o institución se autolegítima mediante el principio de eficacia. Las organizaciones corporativas, en este sentido, perdurarán o no en tanto sean mecanismos eficaces de canalización y filtro de demandas funcionales, y operan como ejes de vertebración del consenso.

En México pareció haber operado así, debido a la ausencia de una verdadera sociedad política (más precisa como público ciudadano moderno), y ese lugar ha sido ocupado por corporaciones tradicionales ${ }^{2}$ como los sindicatos, es decir una toma del espacio público como parte de los intereses particulares encarnados (Rabotnikof, 1992: 35) en las élites sindicales.

Sin embargo, ante la situación de emergencia económica como la que se dio en la década de los $80^{\prime}$ s, con disminución drástica de los salarios reales, mínimos y contractuales, la compresión de las prestaciones sociales y la

2 Desde su creación el corporativismo mexicano se muestra autoritario para todos los sectores, tanto para obreros y campesinos como para la clase media. No es modelo corporativo que favorezca las iniciativas individuales, o un tipo de organización que respete la identidad, y menos aún que propicie el desarrollo de los individuos como ciudadanos. Bertha Lerner "El corporativismo burocrático" en Relaciones corporativas en un periodo de transición, p. 225, Más bien en la negación de la ciudadanía. 
modificación de los contratos colectivos (Zapata, 1992:8) con desventajas para los trabajadores, con respecto a conquistas de años anteriores, las élites sindicales mostraron y dieron su apoyo a las decisiones gubernamentales que se instrumentaron, tanto para aplicar los ajustes como para reestructurar la economía mexicana, aún a costa de vulnerar su capacidad de influir en las decisiones en la nueva estrategia económica, ${ }^{3}$ sobre todo en la política salarial y particularmente en su incapacidad de frenar la pauperización de los trabajadores. Pero además, donde ya no pudieron ayudar y mostrar apoyo fue en el abastecimiento de votos al partido en el poder en las traumáticas -para la élite estatal- elecciones federales de julio de 1988.

Y cada vez más el sistema recibe mayores presiones vía los comicios, debido en buena parte, porque ya no cuenta con la seguridad de que los dirigentes asindicales garanticen el voto de las corporaciones, por ende, debe enfrentar a una sociedad que le reclama participación, muchas ocasiones sin saber a ciencia cierta la forma que ésta debiera adoptar. La vía ideada por el sistema para el descontento que salía de su control tuviera una salida adecuada y manejable, le resulta ahora una fuente constante de inestabilidad (Hernández, 1992:167).

Hasta hace algunos años en México la competencia partidaria y electoral no constituía una preocupación en la medida en que el corporativismo no sólo fue eficaz intermediador social, sino un sello de garantía para que el PRI y el sistema obtuvieran victorias electorales, pero ahora, si en algo es evidente que el corporativismo ha perdido control es en el voto de sus agremiados (Hernández, 1992: 167).

A pesar de que las corporaciones sindicales y sobre todo sus representaciones atraviese por una fase de debilidad y que su actitud sea de una posición defensiva, por haber perdido -en el nuevo contexto-capacidad e influencia en las decisiones en materia económica y que ya no puedan asegurar el cúmulo de votos que antes abastecían el partido en el poder, el corporativismo sigue siendo un mecanismo de intermediación y control social y esto queda mucho más claro con la instrumentación de los pactos de solidaridad ${ }^{4}$ que se establecieron desde diciembre de 1987 a la fecha, Bertha

Lemer (1992) nos ofrece, a este respecto, un buen argumento, al decir que "En las renovaciones del Pacto de Solidaridad se demuestra que el corporativismo aún está vigente como medio de negociación básica, aunque 3 La centralidad de las decisiones de Estado en la nueva regulación económica (la llamada desregulación, que no es otra cosa que una nueva regulación), aleja a las representaciones sindicales de los polos de decisión. Véase Jorge Luis Lozano "el fin del siglo del corporativismo" en: Relaciones corporativas en un periodo de transición.

4 Como dice Francisco Zapata, es evidente que la existencia del modelo corporativo facilita la construcción del modelo de concertación puesto en marcha desde 1987. 
se desvanezca como instrumento gubernamental para garantizar el control social y obtener los votos políticos. Cierto es que en el actual panorama mexicano el vínculo partido oficial -corporaciones se ha debilitado, sin que se entrevea con qué se puede sustituir a las corporaciones dentro del juego político.

Además plantea, que el corporativismo como sistema e imagen monolítica se diluye, pero sin ser completamente abandonada ni sustituida por otra.

En esta óptica y bajo una nueva situación sociopolítica, generada por las políticas económicas, las alianzas entre las élites estatal y sindical se modifican en sentidos al parecer muy delineados y perfectamente bien acotados, aunque en algunos aspectos no muy claros.

Veamos, en un primer plano referido al ámbito de decisiones técnicoeconómico, las relaciones son estrechas y sustancialmente claras, en el cual sin las corporación y el aval y consentimiento de sus dirigencias no podría ser pensable el proyecto económico del régimen.

Aquí las corporaciones son como el canal o el vehículo para la instrumentación de las acciones y decisiones del gobierno, con el costo social y económico que para ellas signifique, incluso para el propio gobierno. En un segundo plano concerniente al ámbito de decisiones político-electorales, las relaciones no son muy claras aún, porque las corporaciones y sus líderes han perdido influencia y capacidad para abastecer el cúmulo de votos que permitan aportan el consenso del régimen, dejando a éste en una situación de un fuerte déficit de legitimidad, pero hasta el momento la élite sindical no sabe como recuperar esa pérdida, y la élite estatal, aún no encuentra o no sabe que los sectores o fuerzas políticas podrían restituirle o compensarle ese déficit de legitimación que hoy padece el sistema político.

El establecimiento de estas nuevas relaciones no han sido fáciles y tranquilas, sino por el contrario complicadas, tensas y en cierto sentido conflictuales entre ambas élites, sobre todo para las élites sindicales que "ya no ocupan el lugar -por demás excepcional- que tenían en las décadas pasadas. Empero los acontecimientos no son homogéneos, y allí donde se ha tenido sus expresiones más "fuertes" el corporativismo no cede con facilidad. Por otra parte, las tendencias no tienen necesariamente consecuencias terminantes, y es lícito pensar que asistimos..., a una transformación de las relaciones corporativas"(Lanzaro: 91)

El corporativismo mexicano como campo de estudios o tema de investigación en los últimos años se ha nutrido de una variedad de enfoques y tratamientos de parte de los estudiosos y analistas dedicados a ello, y cuyas 
vertientes explicativas, descriptivas, prescriptivas y valorativas van orientadas, entre otros, en las siguientes líneas temáticas.

1) El corporativismo mexicano significó la creación de una red sociopolítica y significó también la posibilidad de norm.af el tiempo de las demandas por donde éstas fluían. Luna, 1992: x)

2) El corporativismo como fruto de la centralidad política, dada la degradación del federalismo, en el que el gobierno fungió como eje articulador del Estado y el corporativismo como la forma de su reforzarniento social. Luna, 1992: $\mathrm{x}$ )

3) El corporativismo es el adversario de los neo liberales y de las izquierdas, por el ámbito de una doble condición: la de ser instrumento a través del cual se aplican las medidas de contención económica y, al mismo tiempo, el último de los bastiones de representación de clase en una sociedad regida por un proyecto ideológico-político que tiende a desagregar organizaciones de masas en individuos. (Luna, 1992: $\mathrm{x}$ )

4) El corporativismo como resultado de la hegemonía u Omni presencia del partido dominante. (Trejo, 1990: 194) 5) El corporativismo como la manera de establecerse la relación entre el Estado y las clases subalternas, el corporativismo de Estado (para el caso mexicano) posibilita un control sobre las organizaciones o instituciones, de tal forma que estos grupos se reconocen así mismo en el ámbito institucional. (Aziz, 1990: 44)

6) La relación corporativa ha servido no sólo para que el Estado resuelva autoritariamente conflictos graves, sino también para que la conciliación se mantenga como forma de arreglo. El corporativismo ha sido subordinación al Esta- do, aunque también espacio de influencia y negociación para los sindicatos. (Trejo, 1990: 399)

7) El corporativismo ha sido fuente de estabilidad y seguridad en la producción a la vez que fórmula la estabilidad política según la cual el Estado resulta el grande hacedor, regulador y rector de los grupos y clases en su conjunto.(Trejo, 1990: 190)

Algunos estudios se focalizan a ciertas confederaciones, como la Confederación de Trabajadores de México (CTM) o federaciones como la Federación de Sindicatos de Trabajadores al Servicio del Estado (FSTSE) o Sindicatos nacionales como el Sindicato Nacional de Trabajadores de la Educación (SNTE), e inclusive a organizaciones empresariales, por ejemplo el Consejo Coordinador Empresarial (CCE) y la misma iglesia, dado que el concepto corporativismo (Keller, 1992: 251) se refiere a todo tipo de organización, aunque en nuestro trabajo lo circunscribimos al ámbito de los sindicatos de trabajadores. 
En el presente ensayo, cuyo tema, como ya lo menciona- remos, es la modernización económica y el sindicalismo en los años 1987 a 1992, el corporativismo como concepto será central. Este tiene diferentes acepciones o contenidos, pero también diferentes usos, veamos estos últimos, para luego regresar al plano de la denotación conceptual.

En el marco de las ideas políticas tiene un abanico muy extenso, pero en los años treinta evocaba una gran insistencia a los fascismos.

Después de la Segunda Guerra Mundial, el término corporativismo, siguió ligado ideológicamente al fascismo, sin embargo, también se le utilizó axiológicamente como elemento de crítica y condena política.

En la década de los setenta la politología, de corte anglo- sajón, entrando al rescate, lo retomó -refinando al concepto de su carga normativa- con el objeto de convertirlo en un término que denominará un modelo en clave analítica, que posibilitará “... la descripción y explicación de los sistemas políticos de las sociedad modernas..." especialmente las formas de relación entre poder público e intereses sociales en la formación de decisiones por una parte y por otra “....el término hará referencia a prácticas e instituciones, y no a doctrinas o ideologías proclamadas...” y dará cuenta de su existencia en todas las sociedades modernas, además, desechará, aunque por un corto tiempo, la hipótesis de que el corporativismo estaba ligado a rasgos culturales específicos, a una tradición autoritaria o de atraso político.( Rabotnikof, 1992: 28)

Sin embargo, el modelo fue usado para todos "los regí- menes políticos, a excepción del totalismo, (Bizberg, s/f: 62) aunque principalmente para la democracia de sociedades capitalistas avanzadas.

En este contexto, es que se da el debate acerca de la conceptualización del término corporativo, y con ello también nosotros regresamos al ámbito de lo conceptual.

Los distintos teóricos lejos de ponerse de acuerdo acerca de lo que se designará el concepto y el empleo conceptual del término corporativismo, más bien lo que hace son sustantivaciones del término, otros lo presentan como preferencias normativas y unos más lo caracterizan como inferencias o conexiones causales generales.

Es más o menos extendida la idea de que el corporativismo ofrece una alternativa a los sistemas pluralistas, no sólo en el ámbito de una diferente configuración institucional en la relación entre asociaciones de intereses especializados y procesos políticos, sino también una diferentes conceptualización del papel y la importancia del Estado.

Gerhard Lehmbruch lo concibe como una forma de articular los intereses de los grandes grupos sociales que permitan generar un patrón de forma- 
ción de políticas públicas, de cooperación concertada que implica elección e implementación, así como negociación y representación.

Winkler Pahl lo piensa como un sistema económico, una manera de asignar recursos donde no se ejercen ningún tipo de influencia o de toma de decisiones, por parte de las élites corporativas.

Para Leo Danitch es más importante la dimensión de las relaciones de clase que son asimétricas y contradictorias, y que subyacen en las fórmulas corporativas de las sociedades contemporáneas.

Para autores como Charles W. Arderson, las corporaciones son grandes organizaciones y grupos de interés que no se limitan a satisfacer sus demandas materiales y de reproducción del sistema industrial, sino que también requieren legitimación.

Finalmente Schmitter lo caracteriza como un sistema de representación de intereses, bajo un arreglo institucional que permita vincular los intereses organizados en asociaciones de la sociedad con las estructuras decisionales del Estado.

En el fondo se destaca la conformación de los grupos y organizaciones, sus sistemas de intereses y de actitudes, sus preferencias y demandas, sus sistemas de asociación y representación y el ámbito institucional que los vincule y los articule con los diferentes niveles del Estado, específicamente con aquellos que tiene que ver con la toma de decisiones.

Nosotros utilizamos el término corporativismo en este trabajo en el sentido que lo define Nora Rabotnikov, ya citado en páginas anteriores, que lo conceptual iza como las formas de relación entre poder público e intereses sociales en la formación de decisiones y hará referencia a prácticas e instituciones.

\section{Bibliografía}

Alcocer, Jorge, 1992: "Los partidos políticos en la recomposición de la sociedad civil y del estado en México", documento presentado en el Seminario Transformaciones Sociales y Acciones Colectiva al Finalizar el Siglo $\mathrm{XX}$ : Balances y respectivas Colegio de México

Aziz Nassif, Alberto, 1990: "Las confederaciones obreras y el Estado en México: el caso de la Confederación de Trabajadores de México”. En Documentos de trabajo, No. 34, México: Fundación Friedrich Ebert

Bizberg, Ilán, s/f: El corporativismo en el mundo moderno mimeo, Versión preliminar. 
Bortz, Jeffrey, 1991: "El impacto social en la crisis económica de México" en Revista Mexicana de Sociología, año LIII, No 1 enero-marzo de 1991, México: UNAM.

Cortés, Fernando y Rosa María Rubalcava. 1991: Autoexplotaci6n forzada y equidad por empobrecimiento, México: Colegio de México, colección Jornadas.

Díaz Rivera, Gabriel, 1992: Los caminos de la transici6n politica: Proyecto Nacional y Reforma del Estado, mimeo.

Hernández Rodríguez, Rogelio, 1992: “¿del corporativismo a la contienda electoral?” en: Relaciones corporativas en un período de transicion.

Keller, Berndt, 1992: "Los sindicatos como actores corporativos: intereses de grupo y afectación diferencial" en: Lucien Kern y Hans Peter Múller (comps.), La justicia: ¿Discursos o mercado?, Barcelona: Colina.

Luna, Matilde y Ricardo Pozas H., (coors), 1992: Relaciones corporativas en un período de transición, México: Instituto de Investigaciones Sociales UNAM.

Mayer, Lorenzo et.al, 1989: Seminario reestructuración of fin del corporativismo, México: UAM Xochimilco.

Meyer, Lorenzo, 1991: "El limite neoliberal": en Nexos, núm. 163, julio de 1991, pp. 24-34.

Meyer, Lorenzo, 1992: La segunda muerte de la revoluci6n mexicana. México: Cal y Arena.

Molinar Horcasitas, Juan, 1992: Restructuración económica y realimentos políticos en México, documento presentado en el Seminario, Transformaciones Sociales y Acciones Colectivas al finalizar el Siglo XX: Balances y perspectivas, en el Colegio de México, nov. 1992.

Rabotnikof Nora, 1992: "Corporativismo y democracia: una relación difícil" en: Relaciones Corporativas en un periodo de transición, México: IISUNAM

Revista El movimiento obrero ante la reconversión productiva, México: CTM/ OIT/Fundación Friedrich Ebert.

Rincón Gallardo, Gilberto et al, 1990: México la búsqueda de alternativas, México: Ediciones de Cultura Popular-Facultad de Economía UNAM,.

Schmitter, Philippe C. y Lehmbruch Gerhard (coords), 1992: Neocorporativismo II más allá del Estado y el Mercado, México: Alianza Editorial.

Tiburcio Robles, Jesús Armando, 1992: "Relaciones laborales en el sector público” en Documentos de trabajo No. 37. México: Fundación Friedrich Ebert. 
Trejo Delarbre, Raúl: 1990 Crónica del sindicalismo en México 1976-1988, México: Siglo XXI Editores.

Vázquez Flora, Horacio, 1990: "Políticas de privatización y contratación colectiva. El caso del sector bancario”. En Documentos de trabajo No. 31. México: Fundación Friedrich Ebert.

Villalobos, Gildardo, 1989: "La industria y pequeña de bienes de capital en México" en Documentos de trabajo No. 17, México: Fundación Friedrich Ebert.

Woldenberg, José y Carlos García (Coords.), 1990: Sindicalismo mexicano de los 90's México: Instituto de Estudios para la Transición Democrática/ Fundación Friedrich Ebert.

Zapata, Francisco, 1992: "Modernización económica y sindicalismo en México", documento presentado en el Seminario de Transformaciones sociales y acciones colectivas al finalizar el Siglo XX: Balance y Perspectivas: Colegio de México.

Zepeda, Pedro José (comp.), 1989: "La experiencia de privatización en los países Latinoamérica nos 1982-1988” en Documentos de trabajo, No. 25. México: Fundación Friedrich Ebert. 